\title{
EVALUATION OF LOCAL CAUSES OF EPISTAXIS AND ITS MANAGEMENT OUTCOME IN A TERTIARY CARE HOSPITAL
}

\author{
Rakesh Tripura1, Taranga Reang², Rachit Jain ${ }^{3}$
}

${ }^{1}$ Senior Resident, Department of ENT, Agartala Government Medical College and GB Pant Hospital, Agartala, Tripura.

${ }^{2}$ Assistant Professor, Department of Community Medicine, Agartala Government Medical College and GB Pant Hospital, Agartala,

Tripura.

3Postgraduate Student, Department of ENT, Agartala Government Medical College and GB Pant Hospital, Agartala, Tripura.

\section{ABSTRACT}

\section{BACKGROUND}

Epistaxis is a very common problem. It may be a symptom of minor or serious ailments with underlying local or systemic causes. The objectives of this study are to evaluate various local causes of epistaxis and its management outcome.

\section{MATERIALS AND METHODS}

A descriptive study was conducted among 120 patients who presented with epistaxis of local causes. Individual sampling unit was selected using convenience sampling technique. Nasal pinching, anterior nasal packing and posterior nasal packing were performed in conservative management. Electrocauterisation, septal surgery, nasopharyngeal surgery and endoscopic arterial ligation were considered in surgical intervention. Descriptive statistics like proportion, mean and standard deviation were calculated. For inferential statistics, Chi-square test was performed wherever applicable.

\section{RESULTS}

Males were more compared to females with a male and female ratio of 1.2: 1 . The number of patients were more in winter and autumn; and low during monsoon season. On rhinoscopic examination 53.33\% cases had bleeding from the septum, out of which $81.25 \%$ was from anterior part and $18.75 \%$ was from posterior part of the septum. Most of the nasal trauma was due to road traffic accident. Hippocratic method was performed with a success rate of $80 \%$ to control bleeding.

\section{CONCLUSION}

Traumatic epistaxis was the most common local cause of epistaxis. Cold, dry and low humidity may lead to higher incidence of epistaxis in the winter season. The incidence of epistaxis was higher in young adults and middle-aged people. The anterior nasal packing had more convenient and higher control among all the conservative measures.

\section{KEYWORDS}

Epistaxis, Causes of Epistaxis, Anterior and Posterior Nasal Packing, Surgical Management.

HOW TO CITE THIS ARTICLE: Tripura R, Reang T, Jain R. Evaluation of local causes of epistaxis and its management outcome in a tertiary care hospital. J. Evolution Med. Dent. Sci. 2018;7(14):1760-1764, DOI: 10.14260/jemds/2018/397

\section{BACKGROUND}

Epistaxis is defined as bleeding or haemorrhages from nose, irrespective of any underlying cause. Nose bleeding may be a symptom of different diseases. It may be from a minor ailment or many serious ailments; underlying local or systemic causes. The word "Epistaxis" arises from Greek word "Epistazo" meaning to bleed from nose; epi - on and stazo - to fall in drops from the nostrils.(1) It is a very common problem and estimates on its incidence ranges from $5 \%$ $14 \%$ irrespective of sex. The incidence of epistaxis also shows significant increase during winter months, hot and dry climates with low humidity. In this climatic condition, the nasal mucosa is susceptible to dehydration and subsequent erosion of the superficial submucosal vessels. In the majority of patients, bleeding arises from an artery or vein without

'Financial or Other Competing Interest': None.

Submission 20-02-2018, Peer Review 18-03-2018,

Acceptance 25-03-2018, Published 02-04-2018.

Corresponding Author:

Dr. Taranga Reang,

Assistant Professor

Department of Community Medicine,

Agartala Government Medical College and

GB Pant Hospital, Agartala, Tripura.

E-mail: tarangareang@gmail.com

DOI: $10.14260 /$ jemds/2018/397 any obvious abnormality accounted for it. The increase in incidence of epistaxis has been attributed to increase in the incidence of upper respiratory tract infections. Forceful blowing of inflamed nasal mucosa provokes epistaxis in these patients.(2) Classically, epistaxis is known to manifest bimodal incidence with peak in age groups of adolescent and old age people. Only a small percentage of this population seek Otorhinolaryngological intervention. This amounts to about $1 \%$ of all patients with nasal bleed.(3) Bleeding can be arrested by cautery, anterior or posterior packing by gauze or a 12 - 14 Fr Foley's catheter of a $15-30 \mathrm{~mL}$ balloon. Arterial ligation of anterior and posterior ethmoidal artery was indicated for uncontrolled epistaxis, while uncontrolled posterior epistaxis was managed by ligation of internal maxillary artery.(4) Surgery can be performed by removal of septal spur or deviation septum in recurrent cases. Arterial embolisation, septodermoplasty, laser and cryotherapy can be used to control intractable bleeding.(5)

\section{Aetiology of Epistaxis}

Most causes of nasal bleeding can be identified readily through a directed history and physical examination. The patient should be asked about the initial presentation of the bleeding, previous bleeding episodes and their treatment, comorbid conditions and current medications including overthe-counter medicines, herbal and home remedies. Although, 
the differential diagnosis should include both local and systemic causes,(6) environmental factors such as humidity and allergens also must be considered. Often, no cause for the bleeding is identified.(7) The common causes of epistaxis(8) are: a) Local causes: trauma, rhinitis: both specific and nonspecific granulomatous conditions, sinusitis of various forms, tumours of nose and paranasal sinuses, nasal polyps, irritants (e.g. cigarette smoke), medications (e.g. topical corticosteroids), septal deviation, septal perforation, vascular malformation or telangiectasia and foreign body; b) Systemic causes: haemophilia, hypertension, leukaemia, liver disease (e.g. cirrhosis), medications (e.g. aspirin, anticoagulants, nonsteroidal anti-inflammatory drugs), platelet dysfunction, thrombocytopenia, chronic nephritis, acute general infection, drugs (salicylates, anticoagulant); c) Idiopathic: In many cases the cause of the epistaxis is not clear. The true prevalence of epistaxis is not known, because most episodes are self-limited and thus are not reported. When medical attention is needed, it is either the recurrent or severe nature of the problem. Sufferers and clinicians may develop significant anxiety despite the fact that majority of patients may be treated successfully by the first attending physician. Treatment depends on the clinical picture, the experience of the treating physician and the availability of the ancillary services.(9-11) Seventy percent of the adult males over the age of 60 years have an episode of epistaxis. It has been estimated that nose bleed affects 108 per $1,00,000$ population per year,(12) while it is 30 per 100,000 population.(13) Decisions about the optimum therapeutic intervention and timing are often made on an ad-hoc basis, and most units do not have a protocol (systemic algorithm) for management of epistaxis.(13) It is important whether bleeding is active or controlled, number of episodes, duration and quantity of blood loss to facilitate management by control of bleeding, replacement of blood volume and treatment of hypovolaemic shock.(14) Epistaxis is a common condition prevailing around us and most of the time it is managed without much medical or surgical intervention, but at times it becomes lifethreatening condition to the patient and challenging to the attending doctor. Various magnitude of epistaxis is frequently observed, but a detailed study of the local causes and its management is less commonly found in literature. It is therefore presumed that a systematic study as regards to the causation, its prevention and control would be beneficial in this regard. The objectives of the study are: 1) To evaluate various local causes of epistaxis and 2) Management outcome of epistaxis.

\section{MATERIALS AND METHODS}

This descriptive study was conducted among 120 patients presenting with epistaxis due to local causes to the Department of Otorhinolaryngology and Head and Neck Surgery, Agartala Govt. Medical College and GB Pant Hospital during September 2013 to March 2015 in one and a half years period. Patients presenting with epistaxis were selected by convenience sampling technique irrespective of sex, age, religion and socioeconomic conditions. Patients within the age group of 5 to 70 years of both sexes were included in the study. Patients with systemic causes (cardiovascular diseases including hypertension, haemopoietic diseases, liver disorders, kidney diseases, drugs induced, acute general infections etc.) of epistaxis were excluded from the study.

\section{Data Collection}

Individual sampling unit was selected using convenience sampling technique. Data were collected using structured interview schedule. The patient's age, sex, residence, occupation and admission dates were noted. Amount of blood loss, frequency of bleeding and side of bleeds were also noted. The history of previous attack of epistaxis was also recorded. Family history of blood diseases, hypertension, diabetes mellitus, heart and liver diseases were recorded. Smoking, alcohol intake and drug history (antiplatelets, anticoagulants, steroids, non-steroidal anti-inflammatory) were recorded. Assessment of haemodynamic status was done by general examination and resuscitation was done by fluid replacement or blood transfusion when hypovolaemia occurred. Haematological investigations (Haemoglobin level, haematocrit value, total cell count, differential count, platelet count, bleeding time, clotting time and blood group) were done for all patients if suggested for coagulopathy, activated partial thromboplastin time, prothrombin time, clotting factor assay and blood films accordingly. Paranasal sinuses and nasal bones x-ray was done when bleeding was controlled and in patients with trauma or suspected sinus infection. Nasal discharge sample was sent for culture and sensitivity test. Besides control of epistaxis patient with infection, tumours or any medical illnesses etc. were treated accordingly. Computed tomography (CT) was performed in selected cases if indicated. Biopsy of visible mass for histopathological examination was done. Clearance was obtained from Institutional Ethics Committee of Agartala Govt. Medical College before conducting the study. Informed written consent was obtained from the patients and data so collected were kept confidential and anonymous.

\section{Management Procedure}

Patients were managed with conservative and surgical measures. In this study patients received conservative treatment, failing which patient was subjected to surgical treatment. Nasal pinching (Hippocratic Manoeuvre), anterior nasal packing and posterior nasal packing were performed in conservative management. Electrocauterisation, septal surgery, nasopharyngeal surgery and endoscopic arterial ligation were considered in surgical intervention. A thorough nasal examination including both anterior and posterior rhinoscopy was done and source of bleeding point was found. Nasal endoscopy (with obscured bleeding site) was done for searching the site of bleeding, septal deviations, spurs, masses and polyps or dilated blood vessels or any evidence of infection. Besides it detailed clinical examination of the ear, throat and head and neck region were done.

\section{Hippocratic Manoeuvre or Nasal Pinching}

In case of active anterior bleeding, local pressure application was done by pinching of the nose (ala) with thumb and index finger for the duration of 3 - 5 minutes.

\section{Local Cauterisation}

If bleeding persisted, cauterisation was done for visualised and accessible bleeding point. Electrocautery was used for cooperative adult patients with accessible bleeding site and after desensitising the area with $4 \%$ xylocaine pledget placed for 3 - 5 minutes. 


\section{Anterior Nasal Packing}

It is applied in cases of active bleeding points, failed cases of cauterisation and inaccessible bleeding point. Anterior packing was done with ribbon gauze impregnated with antibiotic measuring around $12 \times 2.5 \mathrm{~cm}$ by using bayonet forceps (Tilley's) and a nasal speculum to place the gauze in a layer from anterior to posterior along with floor of nasal cavity. The gauze was placed as far posteriorly as possible. Under antibiotic coverage packing was kept for 2 - 3 days.

\section{Posterior Nasal Packing}

Failure of the anterior nasal packing and uncontrolled posterior bleeding necessitates posterior packing. Tying three silk to a piece of gauze rolled into the shape of a cone, a rubber catheter is passed through the nose and its end brought out through mouth. Ends of the silk threads are tied to it and catheter withdrawn from nose. Pack, which follows the silk thread, is now guided into the nasopharynx with the index finger. Anterior nasal packing is done and silk threads tied over a dental roll. The third silk was cut short and allowed to hang in the oropharynx.

\section{Septal and Nasopharyngeal Surgery}

Septoplasty, excision of granuloma and angiofibroma which hide a refractory posterior bleeding point.

\section{Statistical Analysis}

Data were collected, shorted, coded and entered in computer. A master chart was prepared for data entry. Descriptive statistics like proportion, means and standard deviation were calculated. For inferential statistics Chi-square test was performed using Epi Info version 6.0 software.

\section{RESULTS}

One hundred and twenty (120) patients were included in the study. The proportion of urban patients was (68.33\%) compared to rural (31.66\%). Males were more (55\%) compared to females (45\%) with a male/female ratio of 1.2:1. The age of the patient varied from 5 to 70 years. The proportion of 15 to 30 years and 45 to 70 years were $35.00 \%$ and $20.00 \%$ respectively (Table 1 ). The number of the patients was more in winter (50 cases) and in autumn (25 cases) and low during monsoon season (7 cases). Patients who presented in summer and spring were 23 cases and 15 cases respectively (Figure 1). On rhinoscopic examination $53.33 \%$ cases had bleeding from the septum, out of which in $81.25 \%$ was from anterior part and in remaining $18.75 \%$ was from posterior part of the septum. In $29.17 \%$ cases, the bleeding was from the lateral wall (Table 2). Various local causes of epistaxis were identified (Table 3 ) and trauma nose accounts for $37.50 \%$. Most of the nasal trauma (37.50\%) was due to road traffic accident (28 cases) followed by physical assault ( 12 cases) and accidental fall ( 5 cases).

It was followed by infection and inflammatory causes $(20.00 \%)$. Least common presentation was foreign body related and found in $5.83 \%$. There were $5.83 \%$ cases of granuloma nose, 3 cases of inverted papilloma and 2 cases of juvenile nasopharyngeal angiofibroma included in the neoplasm causes. Even after detailed clinical and endoscopic examination, the source of bleeding was not found in $12.50 \%$. Histopathological examination, haematological and radiological investigations were done as per requirement to find out the cause that was responsible for the epistaxis (Table 3).

\section{Management of Cases}

To control epistaxis Hippocratic method was performed in 25 cases and out of which epistaxis was controlled in 20 cases with control rate of $80 \%$ and similar success (80\%) was achieved by electrocauterisation. Anterior nasal packing successfully controlled epistaxis in $87.5 \%$, whereas posterior nasal packing was achieved in all the 7 cases (100\%). Nasal and nasopharyngeal surgeries were successfully performed in all 12 cases. Spontaneous controls of epistaxis were seen in 13 cases. The success and failure rates of treatments, i.e. outcomes were tabulated below as shown (Table 4).

\begin{tabular}{|c|c|c|}
\hline Age in Year & No. of Cases (n) & Percentage (\%) \\
\hline $5-15$ & 26 & 21.66 \\
\hline $15-30$ & 42 & 35.00 \\
\hline $30-45$ & 28 & 23.33 \\
\hline $45-70$ & 24 & 20.00 \\
\hline \multicolumn{2}{|c|}{ Table 1. Age Distribution of Patients } \\
\hline
\end{tabular}

\begin{tabular}{|c|c|c|}
\hline Site of Epistaxis & $\begin{array}{c}\text { No. of Cases } \\
\text { (n) }\end{array}$ & $\begin{array}{c}\text { Percentage } \\
\text { (\%) }\end{array}$ \\
\hline $\begin{array}{c}\text { Septum - } \\
\text { (Anterior 52 cases - 81.25\%) } \\
\text { (Posterior 12 cases - 18.75\%) }\end{array}$ & 64 & 53.33 \\
\hline $\begin{array}{c}\text { Lateral wall - } \\
\text { (Inferior turbinate 15 cases - } \\
\begin{array}{c}\text { 42.85\%) } \\
\text { (Middle turbinate/meatus 20 cases } \\
\text { - 57.14\%) }\end{array}\end{array}$ & 35 & 29.17 \\
\hline $\begin{array}{c}\text { Floor } \\
\text { Nasopharynx }\end{array}$ & 04 & 03.33 \\
\hline Unknown Source & 02 & 01.66 \\
\hline Table 2. Sites of Epistaxis of the Patients \\
\hline \multicolumn{2}{|c|}{15} & 12.50 \\
\hline
\end{tabular}

\begin{tabular}{|c|c|c|}
\hline Aetiological Factors & $\begin{array}{c}\text { No. of Cases } \\
\text { (n) }\end{array}$ & $\begin{array}{c}\text { Percentage } \\
(\%)\end{array}$ \\
\hline Trauma nose & 45 & 37.50 \\
\hline Infection and inflammations & 24 & 20.00 \\
\hline $\begin{array}{c}\text { Deviated nasal septum with } \\
\text { spur }\end{array}$ & 18 & 15.00 \\
\hline Environmental & 14 & 11.67 \\
\hline Neoplasm & 12 & 10.00 \\
\hline Foreign bodies & 7 & 5.83 \\
\hline Total & 120 & 100.00 \\
\hline
\end{tabular}

\begin{tabular}{|c|c|c|c|c|}
\hline Measures & $\begin{array}{l}\text { Cases } \\
\text { (n) }\end{array}$ & $\begin{array}{c}\text { Success, } \\
\text { n (\%) }\end{array}$ & $\begin{array}{c}\text { Failure, } \\
\text { n (\%) }\end{array}$ & $\begin{array}{c}P \\
\text { value }\end{array}$ \\
\hline Hippocratic technique & 25 & $20(80 \%)$ & $5(20 \%)$ & \multirow{5}{*}{$>0.05$} \\
\hline Electrocautery & 15 & $12(80 \%)$ & $3(20 \%)$ & \\
\hline $\begin{array}{l}\text { Anterior nasal } \\
\text { packing }\end{array}$ & 48 & $42(87.5 \%)$ & $6(12.5 \%)$ & \\
\hline $\begin{array}{c}\text { Posterior nasal } \\
\text { packing }\end{array}$ & 7 & $7(100 \%)$ & 0 & \\
\hline Surgical intervention & 12 & $12(100 \%)$ & 0 & \\
\hline Spontaneous control & 13 & - & - & \\
\hline
\end{tabular}

Note: Failure cases were subjected to multiple types of treatment. 


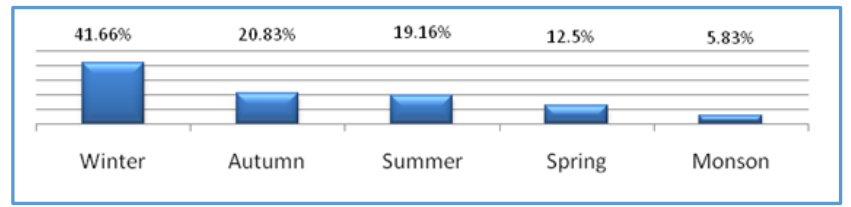

Figure 1. Seasonal Distribution of Epistaxis

\section{DISCUSSION}

Bleeding per nostril or epistaxis is a common sign encountered in otorhinolaryngological cases. It can be treated with simple conservative measures, but occasionally may arise a trouble or a life-threatening condition. Identification of causes of epistaxis is important, as it reflects the treatment plan to be followed. This study had corroborated the fact that epistaxis was a problem of all age groups of population and injury of the nose play an important role as a causative factor. The study demonstrated that patients of epistaxis tend to be more in young adult and middle age group (35\%) than aged people $(20 \%)$. The mean age was 31.87 years, where Hicks and Norris (1989)(15) found a mean age of 47.8 years and mostly older than 40 years in all causes. In this study, males were affected more than females with ratio (M: F) of 1.2: 1 where Arshad MD (2007)(16) showed a ratio of 2.1: 1 in Pakistan. Patients from urban areas were $68.33 \%$ and rural areas were $31.66 \%$. The result is in accordance with Nafi et al (1995),(17) who found 60\% from urban and 40\% from rural area. Nasal trauma cases account for $37.50 \%$ and most common local cause in this study was road traffic accident. The similar result was obtained by McDevitt (1967),(18) who found trauma as the commonest cause (43\%). Among the trauma group, nose picking was $75 \%$ of traumatic causes observed by Razdan et al (1999).(19) There were $41.66 \%$ of patients presented in the winter, which was a maximum number of cases appearing in all the seasons. It was followed by autumn and summer, i.e. $20.83 \%$ and $19.16 \%$ respectively. Ahmed et al (2003)(20) showed that 9\% of patients were during winter. Varshney et al (2005)(21) in India showed that the maximum number (46.59\%) were during January March, while Arshad MD et al (2007) found the maximum number in winter and spring months. It was in accordance with our result, which was supported by result of Rezende GL et al (2009) (22) who found no effect of dry climate on epistaxis and its hospital admission during summer time. In the present study $15 \%$ found to have deviated nasal septum with spur, whereas Daniel M et al (2005)(23) in Leicester, UK observed $24 \%$ cases of epistaxis having deviated nasal septum. Infections and inflammatory causes were $20 \%$ in the present study. Most of them because of frequent upper respiratory tract infections where 6 cases were having pansinusitis, 9 cases bilateral maxillary sinusitis, 5 cases unilateral maxillary sinusitis and 5 cases of rhinitis. The result was almost comparable to result obtained by Vaamonde et al (2000)(24) in Santiago (20\%), whereas Nour YA et al (2008)(25) showed it as the most common cause (65\%); while Razdan et al (2006) in India and Arshad MD (2007) in Pakistan showed inflammatory causes as the third in frequency. Twelve patients (10\%) with epistaxis were due to neoplasm and treated accordingly. Nnennia CM (2004)(26) found that neoplasm constitutes $8 \%$ of all cases. Patients were managed by conservative and surgical measures. In this study patient received conservative treatment, failing which were subjected to surgical treatment.
Nasal pinching, anterior nasal packing and posterior nasal packing were performed in conservative management. Electrocauterisation, septal and sinus surgery, nasopharyngeal surgeries were considered in surgical intervention. The bleeding site was in anterior septal part, especially Little's area in $43.33 \%$ of patients and almost double fold obtained by McDonald (1987).(27) Nasal pinching (Hippocratic technique) applied to 25 cases (20.83\%), where 20 cases were controlled with success rate of $80 \%$. Local cauterisation was applied in $12.50 \%$ cases having active bleeder points and revealed success rate of $80 \%$. Varshney et al (2005) in India regarded cauterising Little's area bleeding with silver nitrate or diathermy was the only treatment needed. The most commonly used treatment was anterior nasal packing in $40 \%$ of patients with a success rate of $87.50 \%$. It was applied in patients with bilateral bleeding points, bleeding not controlled by Hippocratic technique and cautery or in patients with inaccessible bleeding points. Almost similar results were obtained by Nemer AK et al (2008),(28) in which 86 patients with epistaxis were treated by anterior nasal packing. Varshney et al (2005) in India showed that anterior packing is the most commonly used treatment modality in $43.18 \%$ of cases. Posterior nasal packing was done in 5.83\%, whereas Ramesh $\mathrm{P}$ et al $(2015)^{(29)}$ found that posterior nasal packing was required in $16.66 \%$. Septal surgery was performed in 10 cases successfully and two patients of juvenile nasopharyngeal angiofibroma underwent transpalatal excision of the tumour mass. There was none who needed surgical ligation of the bleeding vessels. In this study, there was no mortality. Spontaneous control of epistaxis was observed in $10.83 \%$, mostly seen in traumatic causes without fractured nasal bone. There were no statistically significant differences regarding success rates between different lines of treatment. Similar results were obtained by Nafi et al (2005).(17) The success rates of further treatments were $100 \%$. Shaitkin et al (1987) suggested that surgery be reserved for those in whom the bleeding lasted more than 72 hours in spite of adequate treatment. It was in accordance with a result obtained by us and Nemer AK et al (2008),(28) who found that most cases were successfully managed with conservative medical management alone and surgical intervention with its potential complications may not be necessary in most cases and should be the last resort. The causes of spontaneous nose bleeding were very superficial and the subject needs further investigation. An investigation with an aim of trying to elucidate this problem was planned to be carried out in the near future.

\section{CONCLUSION}

Trauma was the most common local cause of epistaxis. Cold, dry and low humidity weather may lead to higher incidence of epistaxis in the winter season. The incidence of epistaxis was higher in young adults and middle aged people. Anterior nasal packing was more convenient and gives higher control among all the conservative measures. Surgical measures were required in selective cases to control and treat the diseases. Spontaneous control of epistaxis was observed in a few cases. 


\section{Strength and Limitation of the Study}

There is no known similar study conducted earlier in this population group. The study setup was accessible mainly by urban population. We cannot generalise the present study due to small sample size and limited to a hospital only.

\section{Recommendation}

We recommend further studies involving more subjects including rural and urban population. Health awareness activities may be carried out more vigorously throughout the state to cover all population groups.

\section{REFERENCES}

[1] Stedman's Medical dictionary. 22nd edn. Baltimore: The Williams and Wilkins Company 1972.

[2] Chiu TW, McGarry GW. Prospective clinical study of bleeding sites in idiopathic adult posterior epistaxis. Otolaryngol Head Neck Surg 2007;137(3):390-3.

[3] Colman BH. Hall \& Colman's diseases of the nose, throat and ear, and head and neck. A hand book for students and practitioners. 14th edn. Edinburg, New York: Churchill Livingstone 1992: p. 35.

[4] Gray RF, Hawthorne M, Groves J. Synopsis of Otolaryngology $5^{\text {th }}$ edn. Oxford, Boston: ButterworthHeinemann 1992.

[5] Lee KJ. Essential Otolaryngology: head and neck surgery. $8^{\text {th }}$ edn. New York, USA: McGraw-Hill Professional 2003: p. 714 -6.

[6] Koh E, Frazzini VI, Kagetsu NJ. Epistaxis: vascular anatomy, origins and endovascular treatment. AJR Am J Roentgenol 2000;174(3):845-51.

[7] Smith JA. Nasal emergencies and sinusitis. In: Tintinalli JE, Ruiz E, Krome RL. eds. Emergency medicine: a comprehensive study guide. $4^{\text {th }}$ edn. New York: McGraw-Hill Health Professions Division 1996: p. 1082-93.

[8] Dhingra PL. Diseases of ear, nose and throat: epistaxis. $4^{\text {th }}$ edn. New Delhi: Elsevier 2007: p. 167.

[9] Abelson TI. Epistaxis. In: Schaefer D. edr. Rhinology and sinus disease. $1^{\text {st }}$ edn. New York: Mosby 1998: p. 43-50.

[10] Douglas R, Wormald PJ. Update on epistaxis. Curr Opin Otolaryngol Head and Neck Surgery 2007;15(3):1803.

[11] Emannuel JM. Epistaxis. In: Cummings CW. edr. Otolaryngology, head and neck surgery. $3^{\text {rd }}$ edn. St. Louis: Mosby 1998: p. 852-65.

[12] Company BRR. Logan Turner`s diseases of nose, throat and ear. Chapter 14. 10 $0^{\text {th }}$ edn. RR Bowker Company 1988: p. 30.

[13] Flint PW, Haughey BH, Lund VJ, et al. Cumming`s Otolaryngology: head and neck surgery. Chapter 45. Vol 1. $5^{\text {th }}$ edn. Philadelphia, PA: Mosby 2010: p. 682.

[14] Hazarika P, Nayak DR. Clinical operative method in ENT and Head and Neck surgery: a systematic approach (HB). $1^{\text {st }}$ edn. CBS Publishers \& Distributors 2005: p. 32.
[15] Hicks LE, Norris, Hobbs CG. Epistaxis: an update on current management. Postgrad Med J 1989;81(955):309-14.

[16] Arshad M, Ahmed Z, Ali L. Epistaxis: an experience with over 100 cases. ENT Department CMH-Multan 2007;20(3):12-25.

[17] Shehab NM, Shehab AA. Epistaxis: aetiology and management. A thesis conducted in partial fulfilment of the requirements for the degree of fellowship of the Iraqi Board for Medical Specialization, Mousil-Iraq. 2005.

[18] McDevitt TJ, Goh AS, Acquarelli MJ. Epistaxis: management and prevention. Laryngoscope 1967;77(7):1109-15.

[19] Razdan U, Raizada RM. Efficacy of conservative treatment modalities used in epistaxis. Indian Journal of Otolaryngology, Head and Neck Surgery 2006;56:34-9.

[20] Ahmed A, Woolford TJ. Endoscopic biopolar diathermy in the management of epistaxis: an effective and costefficient treatment. Clin Otolaryngology Allied Sci 2003;28(3):273-5.

[21] Varshney S, Saxena RK. Epistaxis: a retrospective clinical study. Indian Journal of Otolaryngology and Head and Neck Surgery 2005;57(2):125-9.

[22] Rezende GL, Granjeiro RC, Furtado PL, et al. Is dry climate correlated with hospitals admissions for epistaxis. Intl Arch Otorhinolaryngol 2009;13(2):1727.

[23] Daniel M, Raghavan U. Relation between epistaxis, external nasal deformity and septal deviation following nasal trauma. Emerg Med J 2005;22(11):778-9.

[24] Vaamonde LP, Lechuga GMR, Minguez BI, et al. Epistaxis: prospective study on emergency care at hospital level. Acta Otolarrinolaringol Esp 2000;51(8):697-702.

[25] Nour YA, Al-Madani A, et al. Epistaxis: Spectrum of diagnostic and treatment modalities. Department of Otorhinolaryngology-Head and Neck Surgery Alexandria University, Egypt, 2008.

[26] Nnennia CM. Epistaxis in Enugu- a 9 year review. Nig J Otorhinolaryngology 2004;1(1):11-14.

[27] McDonald TJ. Nosebleed in children. Background and techniques to stop the flow. Postgrad Med 1987;81(1):217-24.

[28] Al Khtoum N, Al Roosan M. Evaluation of conservative measures in the treatment of epistaxis. Khartoum Medical Journal 2008;1(1):15-17.

[29] Ramesh P. Evaluation of etiology and treatment methods for epistaxis: a review at a tertiary care hospital in central Nepal. International Journal of Otolaryngology Article ID 283854, 2015;2015: p. 5. http://dx.doi.org/10.1155/2015/283854. Accessed on. $5 / 07 / 2017$ 